\title{
Introducing Evidence Based Orthodontics Journal Club Using A Structured Pre And Post Test
}

Muhammad Azeem, Asmi Shaheen, Muhammad Ilyas, Arfan ul Haq, Javed Iqbal, Waheed ul Hamid

\begin{abstract}
Objective: To evaluate the impact of introducing evidence based orthodontics journal club on the performance of postgraduate residents using a structured pre-test and post-test.
\end{abstract}

Study Design and Setting: The comparitive cross sectional study was conducted among the orthodontic postgraduate residents $(\mathrm{n}=30)$ of third year and final year at the orthodontic department at de'Montmorency College of Dentistry, Lahore.

Methodology: Present study was conducted among the orthodontic postgraduate residents $(n=30)$ of third year and final year at the orthodontic department at de'Montmorency College of Dentistry, Lahore. Questions were extracted from the journal club articles. These questions were structured and used in journal club as pre-test and post-test during the academic year 2015-16 and comparison of the performance in the pre-test and post-test over the course of the year was done.

Results: The results of pre-test showed a statistically significant increase during the academic year $(\mathrm{p}=0.031)$. Performance in the post-test also showed a statistically significant increase during the academic year $(\mathrm{p}=0.001)$.

Conclusion: The redesigning of structured pre and post test in orthodontic journal club resulted in significant improvement in the performance of postgraduate orthodontic residents.

Keywords: Evidence Based; Journal Club; Orthodontic; Test.

\section{INTRODUCTION:}

The postgraduate training program in orthodontics requires teaching the knowledge and skills necessary for the understanding and critical reviewing of the orthodontic literature and regular journal club is one of the method to accomplish this goal. ${ }^{1}$ There is a need to reorganize the regularconduction of these monthly journal clubs because of the ongoing issues like attendance, presentation, and active participation of the postgraduate orthodontic residents.

The journal club is an established teaching modality, usually consists of discussion on scientific articles on regular basis

- - - - - - - - - - - - - - 1

I Muhammad Azeem,

I Assistant Professor Orthodontics,

Dental Section-Faisalabad Medical University/ Punjab Medical I

College, Pakistan.

I Email: dental.concepts@hotmail.com

I Asmi Shaheen,

I Assistant Professor Orthodontics,

I de'Montmorency College of Dentistry, Lahore

I Muhammad Ilyas,

Associate Professor Orthodontics,

de'Montmorency College of Dentistry, Lahore

Arfan ul Haq,

Professor of Orthodontics,

I de'Montmorency College of Dentistry, Lahore.

I Javed Iqbal,

I Associate Professor Oral Biology,

Dental Section-Faisalabad Medical University/ Punjab Medical I

College

I

Waheed ul Hamid,

Principal, Professor \& Head, Department of Orthodontics, I de'Montmorency College of Dentistry. Lahore.

I Received: 12-11-18

I Accepted: 22-02-19

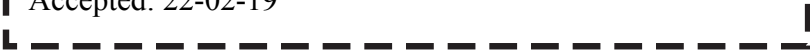

by group of residents in a closed environment. ${ }^{2}$ Traditionally the structure of journal club is to present article by one of the assigned residents followed by discussion on it with other residents. ${ }^{3}$ Its structure can be improved by redesigning it in such a way that it improves performance of residents at the end of academic year. From which one such way is to re-structure the monthlyjournal club by introduction of some sort of evaluation at the start and end of sessions.

A journal club has often a format used to teach evidence orthodontics to residents. ${ }^{1}$ Journal club is a powerful tool to motivate reading behavior of postgraduate residents, and helped in teaching epidemiology and biostatistics to postgraduate residents. ${ }^{4,5}$ Success of journal clubs depends of many factors, such as, regularity, high participation, longevity, availability of food, pre-journal club knowledge of residents, presence of supervisor during journal club. ${ }^{6-9}$

A journal club is an integral part of most postgraduate training programs. ${ }^{10,11}$ The advantages of journal clubs are: learner-centric, problem-oriented, relevant to the resident's recent knowledge, relate theoretical component to clinical, active participation of residents, and enable long-term learning. ${ }^{12-16}$ Postgraduate orthodontic trainees were surveyed at our institute, as a part of needs assessment, to find out issues with the conduct of monthly journal club. The suggestion was reorganizing of monthly journal club by evaluating the performance of postgraduate residents using a structured pre-test and post-test.

The rationale of the present study is that at our orthodontic center, teachers involved with conduct of these monthly journal clubs noted ongoing issues with the presence, presentation, and active participation of the postgraduate orthodontic residents. The postgraduate trainees were 
Muhammad Azeem, Asmi Shaheen, Muhammad Ilyas, Arfan ul Haq, Javed Iqbal, Waheed ul Hamid

surveyed at our orthodontic centre, as a part of needs assessment, to find out issues encountered during monthly journal club. Following this rationale, the objective of present study was to evaluate the impact of introducing evidence based orthodontics journal club on the performance of postgraduate residents using a structured pre-test and posttest.It may also enhance their knowledge and skills.

\section{METHODOLOGY:}

Present study was conducted on the orthodontic postgraduate residents ( $\mathrm{n}=30)$ of third year and final year at the orthodontic department of de'Montmorency College of Dentistry, Lahore. The information of first and second year orthodontic postgraduate residents was collected but not included as they were not informed and trained about such structural changes in the journal club.

TheMultiple choice questions (MCQs)were chosen as a method of evaluating the impact of introducing evidence based orthodontics journal club on the performance of postgraduate residents during the academic year 2015-16. The Multiple choice questions were extracted from the journal club articles assigned to the presenters. The chosen articles were from three orthodontic journals i.e. American journal of orthodontics and dentofacial orthopedics, The Angle orthodontists, and The Seminars in orthodontics. These three journals were chosen because of their well known high impact scores in the field of orthodontics. ${ }^{17-21}$

Well structured MCQs were chosen to demonstrate validity and reliability. Content validity was accomplished through selection of MCQs including the key concepts of evidence based orthodontics. The items were prepared by the head of journal club and prepared both for the pre and post tests.

The data analysis was done using S.P.S.S. version 19.0. Normality of the data was checked. The mean was calculated for each month both for pre and post tests over the course of year.Data analysis was performed by using paired $t$-test to compare the performance by pre-test and post-test. Results were presented using the mean for each month over the course of the year.

\section{RESULTS:}

From the total $(\mathrm{n}=30)$ of third year and final year residents of post graduate orthodontic residents; the analysis of the data showed that data were normally distributed so pre-test scores was presented using the mean for each month. Pretest performance improved from $49 \%$ to $77 \%$ over the course of year with the significant linear trend.Results of the pre-test showed a statistically significant increase during the academic year $(\mathrm{p}=0.031)$.

Post-test performance improved from $59 \%$ to $82 \%$ over the course of year with the significant linear trend. Performance in the post-test also showed a statistically significant increase during the academic year $(\mathrm{p}=0.001)$. (Table 1$)$

\begin{tabular}{|c|c|c|c|}
\hline Month & $\begin{array}{r}\text { Mean } \\
\text { Pre \% }\end{array}$ & $\begin{array}{c}\text { Mean } \\
\text { Post \% }\end{array}$ & \% Difference \\
\hline $\mathbf{1}$ & 49.34 & 59.76 & 18.45 \\
\hline $\mathbf{2}$ & 45.32 & 61.45 & 35.67 \\
\hline $\mathbf{3}$ & 59.09 & 73.52 & 24.55 \\
\hline $\mathbf{4}$ & 54.78 & 74.56 & 32.55 \\
\hline $\mathbf{5}$ & 61.03 & 74.56 & 26.45 \\
\hline $\mathbf{6}$ & 53.4 & 72.45 & 39.43 \\
\hline $\mathbf{7}$ & 73.45 & 75.67 & 49.34 \\
\hline $\mathbf{8}$ & 71.34 & 65.42 & 10.45 \\
\hline $\mathbf{9}$ & 74.63 & 75.96 & 1.56 \\
\hline $\mathbf{1 0}$ & 75.21 & 78.43 & 4.57 \\
\hline $\mathbf{1 1}$ & 76.45 & 79.54 & 2.53 \\
\hline $\mathbf{1 2}$ & 77.56 & 82.66 & 4.79 \\
\hline P value & 0.031 & 0.001 & 0.039 \\
\hline Mean & 58.23 & 73.24 & - \\
\hline S.D & 9.32 & 18.32 & - \\
\hline
\end{tabular}

Table I: Comparison of scores in the Orthodontic journal club $(\mathrm{n}=30)$

\section{DISCUSSION:}

Results of the present study found that pre-test showed a statistically significant increase during the academic year i.e. pre-test performance improved from $49 \%$ to $77 \%$ over the course of year with the significant linear trend. This is in accordance with the results of study by Cramer et al., showed that the incorporation of a pre-test/post-test structure resulted in significant increase of the performance of the residents in pre-test during the academic year of Evidence Based Medicine. ${ }^{22}$ The pre-test allowed trainees to begin to track in a structural manner and it pointed out the trainees with problems or lack of active participation.

In our study the performance in the post-test also showed a statistically significant increase during the academic year i.e. post-test performance improved from $59 \%$ to $82 \%$ over the course of year with the significant linear trend. These results were in accordance with the results of study by Cramer et al., who showed that the incorporation of a pretest/post-test structure resulted in significant increase of the performance of the residents in post-test during the academic year of Evidence Based Medicine. ${ }^{22}$ The post-test allowed trainees to reinforce and facilitate positive change in structuring of journal club.

Limitations of the study were its small sample size, and was conducted at one orthodontic center. Further large scale multi-centric studies with better methodology are suggested.

Our recommendation is that structural changes should be applied in the orthodontic journal club using pre-test and post-test, as it may improve the performance of residents at the end of academic year. 


\section{CONCLUSION:}

The redesigning of structured pre and post test in orthodontic journal club resulted in significant improvement in the performance of postgraduate orthodontic residents.

\section{REFERENCES}

1. Rossouw PE. Orthodontic postgraduate education: A global perspective. American Journal of Orthodontics and Dentofacial Orthopedics. 2017;151(1):225-6.

2. Wenke RJ, Thomas R, Hughes I, Mickan S. The effectiveness and feasibility of TREAT (Tailoring Research Evidence and Theory) journal clubs in allied health: a randomised controlled trial. BMC medical education. 2018;18(1):104.

3. Tsui IK, Dodson WC, Kunselman AR, Kuang H, Han FJ, Legro RS, Wu XK. Chinese Obstetrics \& Gynecology journal club: a randomised controlled trial. BMJ open. 2016;6(1):e010178.

4. Linzer M, Brown JT, Frazier LM, DeLong ER, Siegel WC. Impact of a medical journal club on house-staff reading habits, knowledge, and critical appraisal skills: a randomized control trial. JAMA. 1988;260(17):2537-41.

5. Alguire PC. A review of journal clubs in postgraduate medical education. Journal of General Internal Medicine. 1998;13(5):347-53.

6. Topf JM, Sparks MA, Phelan PJ, Shah N, Lerma EV, GrahamBrown MP, Madariaga H, Iannuzzella F, Rheault MN, Oates T, Jhaveri KD. The evolution of the journal club: from Osler to Twitter. American Journal of Kidney Diseases. 2017;69(6):827-36.

7. Lucia VC, Swanberg SM. Utilizing journal club to facilitate critical thinking in pre-clinical medical students. International journal of medical education. 2018;9:7.

8. Xiong L, Giese AK, Pasi M, Charidimou A, van Veluw S, Viswanathan A. How to Organize a Journal Club for Fellows and Residents. Stroke. 2018 Jan 1:STROKEAHA-118.

9. Nason GJ, O'kelly F, Kelly ME, Phelan N, Manecksha RP, Lawrentschuk N, Murphy DG. The emerging use of T witter by urological journals. BJU international. 2015;115(3):48690.

10. Kelly BS, Redmond CE, Nason GJ, Healy GM, Horgan NA, Heffernan EJ. The use of Twitter by radiology journals: an analysis of Twitter activity and impact factor. Journal of the American College of Radiology. 2016;13(11):1391-6.
11. Hohmann E, Tetsworth $\mathrm{K}$. Teaching residents: critical appraisal of the literature using a journal club format. Postgraduate medical journal. 2016 Apr 22:postgradmedj-2015.

12. Chan TM, Thoma B, Radecki R, Topf J, Woo HH, Kao LS, Cochran A, Hiremath S, Lin M. Ten steps for setting up an online journal club. Journal of Continuing Education in the Health Professions. 2015;35(2):148-54.

13. Thangasamy IA, Leveridge M, Davies BJ, Finelli A, Stork B, Woo HH. International urology journal club via Twitter: 12-month experience. European urology. 2014;66(1):112-7.

14. Jamal AB. Journal club: An Important Teaching-Learning Activity. Journal of Bangladesh College of Physicians and Surgeons. 2016;33(4):213-7.

15. Ferguson C, DiGiacomo M, Gholizadeh L, Ferguson LE, Hickman LD. The integration and evaluation of a socialmedia facilitated journal club to enhance the student learning experience of evidence-based practice: A case study. Nurse education today. 2017;48:123-8.

16. Laaksonen C, Paltta H, Shantz MV, Ylönen M. Journal club as a method for nurses and nursing students' collaborative learning.

17. Howell J, Little R, Harrison J. Relevant research from orthodontic journals. Journal of orthodontics. 2017;44(2):1414.

18. Kanavakis G, Dombroski MM, Malouf DP, Athanasiou AE. Demographic characteristics of systematic reviews, metaanalyses, and randomized controlled trials in orthodontic journals with impact factor. European journal of orthodontics. 2015;38(1):57-65.

19. Tidbury KL, Turner S, Ulhaq A. Origin and type of articles published in four mainstream orthodontic journals: a fiveyear study. Orthodontic Update. 2017;10(2):73-6.

20. Prasanna MK, Handa A, Nehra K, Sharma M. Trends in contemporary orthodontic research publications: Evaluation of three major orthodontic journals. APOS Trends in Orthodontics. 2017;7(6):287.

21. Kanavakis G, Spinos P, Polychronopoulou A, Eliades T, Papadopoulos MA, Athanasiou AE. Orthodontic journals with impact factors in perspective: trends in the types of articles and authorship characteristics. American journal of orthodontics and dentofacial orthopedics. 2006;130(4):516-22.

22. Cramer JS, Mahoney MC. Introducing evidence based medicine to the journal club, using a structured pre and post test: a cohort study. BMC Medical Education. 2001;1(1):6. 